ON THE RECORD

“Even on the most solemn occasions I got away without wearing socks and hid that lack of civilization in high boots.)”

A newly released letter by Albert Einstein reveals his sartorial secrets.

“There were meateating kangaroos with long fangs, and galloping kangaroos with long forearms, which could not hop.")

Palaeontologist Mike Archer describes some of the 20 extinct species found by his team on a fossil dig in northwest Queensland, Australia.

Sources: New Scientist, BBC

\section{SCORECARD}

Chinese music Officials in China are asking the public to pick 30 songs to be broadcast from the country's first lunar probe, scheduled to launch next year.

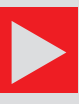

\section{Opera singing}

Scholars in Bologna dig up the body of the world's most famous castrato singer, Farinelli, to study the physical attributes that gave him his renowned voice.

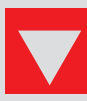

\section{Fish stocks}

Overfishing has led to a 'jellyfish explosion' in the waters off Namibia, where the biomass of the gelatinous pests is three times that of fish.

\section{NUMBER CRUNCH}

The Worldwatch Institute has mixed news about global energy trends.

$19 \%$ was the amount the production of ethanol for fuel went up by between 2004 and 2005.

$\mathbf{2 4} \%$ was how much global windpower capacity increased last year.

$\mathbf{8 0} \%$ of the world's energy was derived from fossil fuels in 2005.

14.6 ${ }^{\circ} \mathrm{C}$ was the average global temperature in 2005 - the warmest year on record.

Source: The Worldwatch Institute

\title{
Concerns grow over secrecy of bubble-fusion inquiry
}

As a way to resolve a scientific dispute, it was always likely to be fraught. In March 2005, nuclear engineer Rusi Taleyarkhan of Purdue University in West Lafayette, Indiana known for his controversial claims to have achieved 'bubble fusion' - formally joined forces with one of his most prominent critics, physicist Seth Putterman of the University of California, Los Angeles.

But few could have predicted that this collaboration would end in such disarray. After concerns about Taleyarkhan's work were reported in Nature earlier this year ${ }^{1}$, Purdue carried out an inquiry, but has shrouded the results in confidentiality, a decision that has frustrated other researchers in the field. The findings could resolve the long-standing controversy surrounding bubble fusion, but whether they will ever be made public now seems to rest on a technicality: did $\$ 250,000$ of US taxpayers' money help fund the disputed work?

The story began in 2002, when Taleyarkhan reported fusion in collapsing bubbles within a liquid, an effect also called sonofusion ${ }^{2}$. His work made headlines worldwide: if the effect could be harnessed, it would promise almost unlimited energy. But others in the field were not convinced.

In the hope of settling the resulting argument, in March 2005 DARPA, the Pentagon's research agency, paid Taleyarkhan and his crit- ics to work together to replicate the bubblefusion experiment. Putterman was principal investigator on the $\$ 812,000$ grant and so has to account for all the expenditure. Taleyarkhan was allocated $\$ 318,000$ of the grant, and Ken Suslick of the University of Illinois at UrbanaChampaign was given $\$ 145,000$.

It was clear things weren't going well when concerns about the validity of Taleyarkhan's bubble-fusion work were reported on $8 \mathrm{March}^{1}$. These included an analysis by Putterman's postdoc, Brian Naranjo ${ }^{3}$, showing that the neutrons described in Taleyarkhan's latest paper, published in Physical Review Letters (PRL) in Janu$\operatorname{ary}^{4}$, came not from fusion as claimed but from the radioactive decay of standard lab material.

Purdue's provost Sally Mason called the reports "very serious" and announced a threemonth review, the outcome of which she promised to publish. But once the review was complete, Purdue said the results and any future steps would be kept internal and confidential. On completion of a review, Purdue's stated policy is either to close the matter or to proceed to a fully fledged misconduct investigation. The university won't say which has occurred.

Many in the field are disappointed by the lack of information, including Putterman. He is sure that money from the shared DARPA grant was used for the work Purdue reviewed, so he is particularly keen to know whether an

\section{WHERE DID THE MONEY GO?}

The DARPA grant awarded to Seth Putterman and Rusi Taleyarkhan for work on bubble fusion began in March 2005, and Taleyarkhan submitted a paper to Physical Review Letters (PRL) that September ${ }^{4}$. Taleyarkhan insists no DARPA money was used for that work, but after checking accounts at Purdue University, where Taleyarkhan is based, Putterman believes otherwise.

- According to Purdue's accounts, the DARPA grant was billed for one-third of Taleyarkhan's salary from March until May 2005, all of it from June to August, and one-fifth of it from September to December.

- At least $\$ 25,000$ of the grant money was transferred to Taleyarkhan's former collaborator JaeSeon Cho at Oak Ridge National Laboratory in Tennessee. The PRL paper thanks Cho for his "in-depth advice and ongoing technical assistance and cross-checks".

- Taleyarkhan's postdoc, Yiban Xu, was a co-author on the PRL paper. The DARPA grant paid all of his salary for March and April 2005, and at least half of it from May until December. (Xu's salary was originally billed at $100 \%$ for part of this latter period, but a partial refund was made in March 2006.)
- The experiment described in the PRL paper is the same as the one Taleyarkhan demonstrated to his DARPA programme manager, William Coblenz, at a meeting on 1 March 2006 to assess progress of the DARPAfunded work.

- None of Taleyarkhan's other grants, according to a list provided by Purdue University, includes the word 'sonofusion' in the title. 


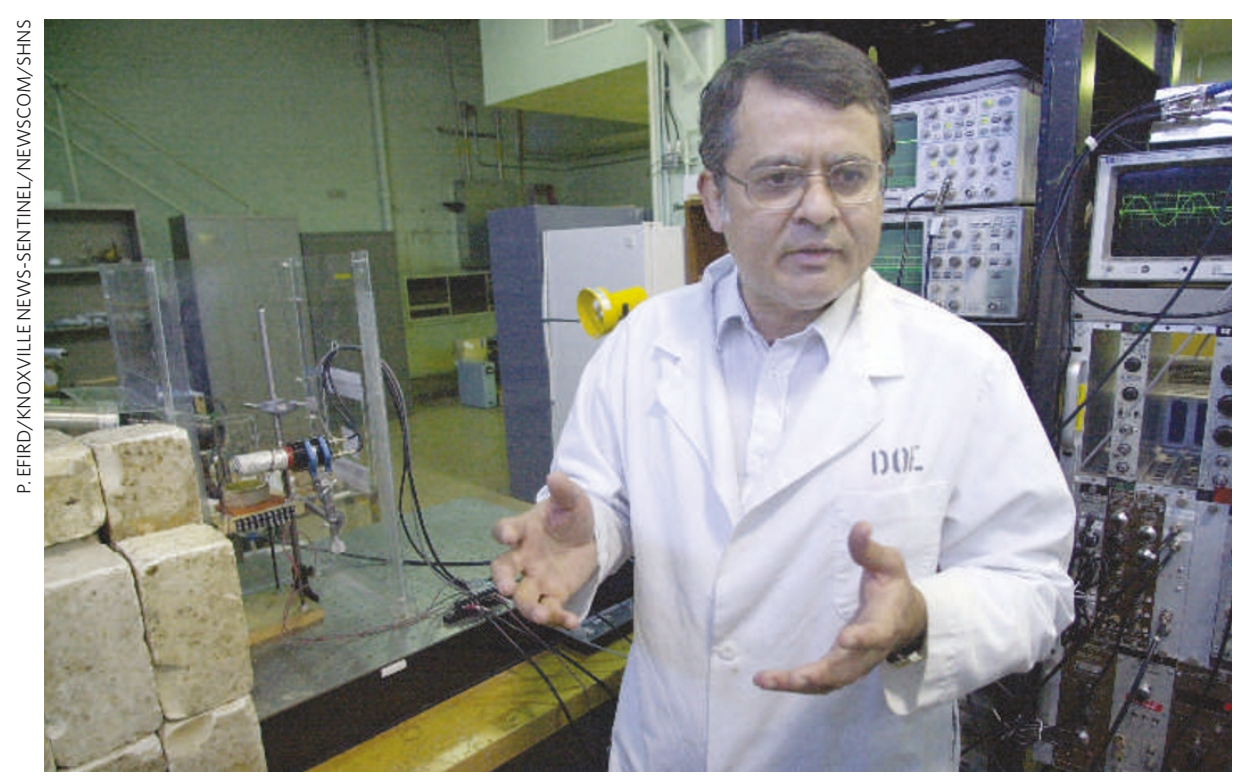

Rusi Taleyarkhan denies that federal dollars funded certain aspects of his research.

investigation is under way. "As a principal investigator, do I have any right to know what's happening on my project?"

In cases where federal money is involved, there is a responsibility to tell the government and the taxpayer how it was spent - and any misuse of federal dollars can have serious consequences for the researchers involved. If DARPA money was used for any of the disputed work, Purdue would be required to notify the agency of any investigation, and share information relating to it. Such communications could eventually be made public under the US Freedom of Information Act.

Taleyarkhan did not acknowledge the DARPA grant in the January $P R L$ paper. But when Nature asked Putterman to confirm no DARPA money was used, he requested the relevant accounts from Purdue. Putterman now says: "I've "As a principal investigator, do I have any right to know what's happening on my project?" months before the paper was submitted, and that start-up funding from Purdue paid for them. (The university told Nature that this funding totalled $\$ 58,607$.) He adds that he and the others involved worked on the project outside the normal eight-hour day.

In the e-mail, Taleyarkhan also says that the bubble fusion described in the PRL paper is different from that reported in his previous papers, on which he has warmly acknowledged DARPA funding. He does not give details of what the $\$ 251,044$ of DARPA money he spent was used for, if not the disputed work.

Taleyarkhan's explanation may make little difference if the case is investigated. "If any part of salary is allocated to a grant awarded by a federal agency, then federal funding is involved," says Mark Frankel, director of the Scientific Freedom, Responsibility and Law programme at the reviewed the books, and I am confident that the paper relied on federal money that was not acknowledged." For example, Taleyarkhan and his colleagues claimed DARPA salaries in the run up to submission of the $P R L$ paper (see 'Where did the money go?').

Taleyarkhan has declined to communicate with Nature directly. But he said through a third party - Brian Josephson at the University of Cambridge, UK - that Putterman's interpretation of how the work was funded is "off-base and wrong". Josephson also provided part of an e-mail in which Taleyarkhan strongly denies using the DARPA grant on the disputed work. Taleyarkhan says the experiments were completed by May 2005, several
American Association for the Advancement of Science in Washington DC. Nature has confirmed this general interpretation with an investigator at a federal funding agency.

Purdue says it has not queried Taleyarkhan's assertion that no federal money was used. "The authors of the paper are the best source of information on the source of support for research," says a spokesman. "We have no reason to question the source of support stated." Eugenie Samuel Reich

\footnotetext{
1. Reich, E. S. Nature doi:10.1038/news060306-1 (2006)

2. Taleyarkhan, R. P. et al. Science $\mathbf{2 9 5}, \mathbf{1 8 6 8 - 1 8 7 3}$ (2002)

3. Naranjo, B. preprint at www.arxiv.org/abs/physics/ 0603060 (2006).

4. Taleyarkhan, R. P. et al. Phys. Rev. Lett. 96, 034301 (2006).
} 